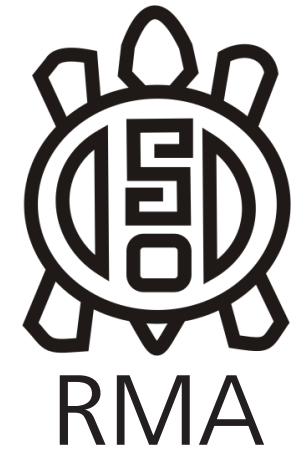

Dossier

Wichí: La gente

\section{Apuntes para una "etnografía centrada en la persona" con los wichís del Chaco argentino}

\author{
Notes for a "personal focused ethnography" with the wichis of the \\ Argentinean Chaco
}

*Zelda Alice Franceschi

*Università degli Studi di Bologna, DISCI, \& Centro de Investigaciones Históricas y Antropológicas (CIHA). E-mail: zelda.franceschi@unibo.it

\begin{abstract}
Resumen
Este artículo se propone, en primer lugar, una reflexión sobre la metodología de trabajo en antropología; se observa cómo las prácticas de investigación y el paradigma disciplinario no favorecen y no requieren una aclaración sistemática de la metodología. En segundo lugar, se presentan las prerrogativas del método biográfico que permite una etnografía sensible y bien atenta a la "persona". Por último, se introducen algunos testimonios de mujeres wichís del Chaco argentino que viven actualmente en Misión Nueva Pompeya. Se trata de relatos que fueron contados en castellano, uno de ellos traducido de la lengua wichí junto con un joven estudiante. En estos testimonios, los protagonistas reflexionan sobre el significado de algunas expresiones verbales, proponiendo traducciones nocionales y explicando sus contextos de uso.
\end{abstract}

Palabras clave: Historias de vida; Antropología de la persona; Palabras; Wichí.

\begin{abstract}
The paper proposes, on the one hand, a reflection on the anthropological methodology. It analyzes how the disciplinary paradigm and research practices neither encourage nor require a systematic clarification of the implicit methodology. On the other hand, the prerogatives of the biographical method are presented, which allows for a sensitive ethnography that tries to be particularly attentive to the "person" factor. Finally, some testimonies of current Wichis women from Misión Nueva Pompeya in the Argentinian Chaco are introduced. These stories were mainly told in Spanish and one of them was translated from the Wichi by the author itself with a young Wichi student. In these testimonies, the protagonists reflect on the meaning of some verbal expressions, propose notional translations, and explain their contexts of use.
\end{abstract}

Keywords: Life Story; Anthropology of the Self; Words; Wichi.

\section{El trabajo de campo}

Desde el principio de mi carrera como antropóloga, mi obsesión fue la metodología. La ilusión difundida en mi grupo de doctorado era que un buen armazón metodológico resolviera o por lo menos disipara las angustias provocadas por la etnografía. En la historia de la antropología -europea y americana- la etnografía (la caja de herramientas con la que el antropólogo llegaba al campo) y su elaboración en modelos de conocimientos no encontraron un equilibrio estable. La etnografía en su tradición más clásica y por razones que están bien radicadas en un paradigma disciplinar híbrido y muy joven, siempre ha admitido un desbalance entre la representación histórico-cultural y lingüística en su aparato teórico y su contracara etnográfica ${ }^{1}$. La metodología quedó como algo no discutido y poco compartido en una comunidad académica que dejó en una anarquía -silenciosa y cómplice- sus códigos deontológicos. Los etnógrafos se encontraron con unas prácticas bien borrosas, cuyas aplicaciones quedaban

\footnotetext{
${ }^{1}$ En 1874 la British Association for the Advancement of Science publicó en Londres la primera edición de Notes and Queries on Anthropology for the Use of Travelers and Residents in Uncivilized Lands. La sexta y última edición se publicó en 1951. En 1947 Marcel Mauss publicó su Manuel d'ethnographie. Es llamativo que en la historia de la disciplina otros títulos sobre metodología etnógrafica se refieren sobre todo al tema de la autobiografía y las historias de vida. Sobre los diarios, las notas de campo y la práctica etnográfica, ver Sanjeck, 1990.
} 
regidas por su buen corazón. Ronald Campbell y Roberta Levine escribieron algo muy sencillo:

cada estudiante que hace trabajo de campo para su disertación se adentra en un área única, la estudia con un conjunto de métodos propios, a los que su propia y única personalidad contribuye en gran medida, y llegada la hora debe centrarse en una hipótesis única y un contenido único. La idiosincrasia que resulta en un informe etnográfico tiene como éxito pocas posibilidades de ser interpretable $\left(1970\right.$, p. 366) ${ }^{2}$

La etnografía se adapta al aprendizaje lingüístico del investigador, que cambia si se conoce la lengua de la comunidad o si se usa una de las lenguas vehiculares que -hoy en día- habla una parte considerable de las personas con quienes conducimos nuestra investigación. Tullio De Mauro, lingüista y académico italiano, nombrado Ministro de Educación Pública en el año 2000, refiriéndose al uso de la lengua, argumenta que "no es un sistema, sino un vínculo geo-histórico, espacial y temporalmente variable para cada una de las áreas en las que hablamos idiomas" (2009, p. 29). De Mauro utiliza una palabra buena para pensar -vínculo-que perfectamente encuadra una problemática central para el etnógrafo.

Otra de mis obsesiones -más feliz, en todo caso- fue el trabajo de Franz Boas. Mi interés oscilaba entre lo biográfico-autobiográfico (sus diarios, sus cartas, sus escritos más periodísticos) y lo más teórico. Boas, o "Papa Franz", como lo llamaban sus discípulos, quienes propusieron con tenaz obstinación una "etnografía centrada en la persona" (personal focused ethnography) ${ }^{3}$, fue un antropólogo atento para su época por lo menos, al aparato lingüístico ${ }^{4}$, a pesar de su mínima formación en ese campo (Darnell, 2001, p. 48). En el prefacio de su Handbook of American Indian Language, Boas se preguntaba por qué se suponía que aquellos tratados sobre la civilización china o japonesa, o sobre el mundo clásico, sólo tenían autoridad si quienes los escribían tenían un dominio completo de la lengua o literatura oral, mientras que entre los etnólogos era común "estar a punto de ilustrar los pensamientos y sentimientos más ocultos de un pueblo sin siquiera tener un conocimiento básico del idioma" (1911, p. 60). Mientras que Boas y sus discípulos se afanaban en escribir el Handbook, el antropólogo alemán tenía en mente la importancia de los textos registrados en el trabajo de campo a los que consideraba "el mejor material que poseemos". Pero, no cualquier texto era importante, sino los que "ellos mismos [los nativos] escriben e imprimen y distribuyen como

\footnotetext{
${ }^{2}$ Nuestra traducción.

${ }^{3}$ La expresión es de Regna Darnell (2001, p. 13). En 1938, Marcel Mauss desarrolló la noción de persona en Occidente, pero Darnell se refiere aquí principalmente a un enfoque biográfico y autobiográfico.

${ }^{4}$ No faltaron las críticas a sus traducciones; según la opinión de Rohner, los textos de Boas y otros materiales etnográficos analizados contienen inexactitudes e inconsistencias. Él era consciente de estas dificultades y nunca las corrigió (1969).
}

noticias, con el fin de informar a la gente de todos los eventos que son de interés. Estos textos solían contener mucho material mitológico relacionado con el modo de vida de la gente" (Franz Boas Professional Correspondence 1911, en Berman, 1996, p. 223). A principio del siglo XX, Boas se detenía en la escritura nativa y la consideraba algo de incalculable valor; los textos contenían "las costumbres peculiares y el carácter de la gente" (Boas 1889, en Stocking 1974, p. 86). Qué entendía realmente Boas con "carácter" (character) es algo que no podemos resolver en estas páginas, pero -como en el caso del "vínculo"queda algo muy bueno para poner sobre nuestra mesa de trabajo. También es preciso subrayar que los textos que menciona Boas eran mayormente transcriptos por él; son varias las notas que dejó en sus cuadernos sobre este tema:

\begin{abstract}
Ayer dos jóvenes aparecieron y se rieron cuando escucharon al viejo hombre contar historias. Él se avergonzó y dijo que se negaría a hablar si otros estaban presentes. Cada cinco minutos me asegura que es el mejor entre todos los hombres de aquí y que sabe todo [...]. El viejo se fija en que yo anote cada palabra que él dice, y, si no lo hago, lo toma como un insulto personal y hace un largo discurso del que no entiendo ni una palabra (8 de noviembre de 1886, en Rohner 1969, p. 55).
\end{abstract}

Como la carismática Cassandra, Boas, con sus cuadernos, sus cartas y sus notas, profetiza a los futuros antropólogos un destino casi ridículo en sus esperanzas y desengaños.

Por mi parte -como siempre pasa-, no resolví mis obsesiones. Empecé tarde mi trabajo de campo y no tengo todavía un conocimiento de la lengua local que me permita hablar fluídamente con la gente wichí del Chaco argentino, a la que, sin embargo, visito desde hace tiempo para desarrollar mis investigaciones ${ }^{5}$. Por otra parte, la metodología biográfica que siempre empleé fue un atajo -no tan fácil, no tan rápido ni tan simplepara gestionar y compensar la cuestión lingüística. La verdad -si existe alguna- es que un antropólogo debería conocer la lengua local. La realidad -que sí existe, porque es nuestro pan cotidiano- revela que el conocimiento del etnógrafo de la lengua de la gente que estudia no es algo todavía demasiado difundido, y es bien complicado. Las preguntas, entonces, son a la vez simples y puntuales: ¿Podemos arriesgarnos a hacer etnografías o investigaciones socioculturales aunque nuestra competencia en la lengua vernácula sea aún rudimentaria? Y, a la inversa, ¿qué valor tiene un conocimiento detallado de la lengua (de su gramática, de su morfosintaxis), cuando el aporte a la comprensión sociocultural es casi insignificante o queda olvidado en un rincón? Dicho de otra manera, ¿podemos hacer

\footnotetext{
5 Trabajé desde 2004 en Misión Nueva Pompeya hoy uno de los siete municipios del departamento de General Güemes y que tiene alrededor de 4.500 habitantes, la mitad de los cuales son wichís.
} 
etnografía con palabras "vacías", palabras cuyo ethos -en el sentido de "trasfondo emocional" que le dio Bateson (1988, p. 8) en Naven- está completamente omitido o, en el mejor de los casos, ha sido marginado? ¿qué pasa cuando el trato lingüístico no tiene correspondencia con sus características indexicales? La relación entre los aspectos verbales y extraverbales: los gestos, la posición del cuerpo, la dirección de la mirada, el tono de la voz y al mismo tiempo la fuerza ilocutiva son todos elementos que revelan cuanto el habla es "un hacer", una acción social y que cada lengua tiene sus prácticas referenciales. Antropólogos del lenguaje, lingüistas y etnógrafos hablan todavía -y eso parece un verdadero trabalenguasidiomas diferentes. Con un esnobismo elegante pero un poco despectivo, Alessandro Duranti decía que muchos lingüistas, aunque ocasionalmente puedan participar de la vida de la comunidad, no consideran que el hecho de estar allí sea una oportunidad para captar el uso que los hablantes hacen de su idioma; para ellos, más bien, el trabajo de campo es una oportunidad para entrenar (train) a los hablantes nativos y convertirlos en consultantes que, muñidos de su intuición lingüística, puedan emitir juicios sobre la aceptabilidad gramatical de tal o cual enunciado: "¿Cuál es la mejor estructura? ¿Qué hay que no funciona en esa? ¿Y tú cómo lo dirías?" (Duranti, 2000, p. 95).

Desde el punto de vista metodológico, interesarse en el conocimiento lingüístico y proponer una "etnografía centrada en la persona" permitiría una visión del contexto cultural que prioriza, no tanto los rasgos típicos o las diferencias estereotipadas, sino las estrías, las zonas de sombras, las franjas de la cultura poco exploradas porque le causan vergüenza (en wichí, nojwel) o temor (en wichí, noway) a los mismos actores. El propio Boas tuvo una brillante intuición al señalar que incluso en las sociedades tradicionales ("primitivas"-así las llamaba) los individuos luchan "contra las costumbres tribales" para liberarse "de las raíces de las convenciónes" (1940, p. 638). Según Boas, el individuo con sus ideas, a través de sus proyectos y con una cierta creatividad, podía situarse más allá de los límites marcados por la cultura, transgredir o ponerse al margen de las normas establecidas, teniendo así la oportunidad de observar su propia cultura desde arriba. La imagen que propone Boas es la de un individuo que, con sus idiosincrasias, su carácter y su personalidad, puede ponerse críticamente y manifestar su "incomodidad" hacia los patrones culturales. En el Chaco indígena, un ejemplo bien claro de lo que voy diciendo es el criollaje. Por razones históricas, económicas y culturales $^{6}$, que tienen como constante una violencia criolla persistente, el criollaje es considerado por los wichís como un elemento de degradación, y como tal, culpado y recriminado. Se trata además de un tema poco tratado en la literatura. Entre los mismos wichís es algo que provoca malestar, argumento que se pospone y que se deja correr tratándolo de manera vaga. Hay prejuicios étnicos y socio-culturales que persisten en ambos lados y lo que resulta evidente es

\footnotetext{
${ }^{6}$ Cfr. Millán, 1959; Montani, 2008; Palmer, 2005; Sturzenegger, 1999.
}

una angustia padecida por los wichís, que se concreta en la incapacidad de reacción por falta de confianza o por temor, sentimientos que continuamente son afirmados y confirmados por los hechos. La relación wichís-criollos está salpicada de frustraciones, caracterizada por una constante imposibilidad de comunicación. Los criollos que se establecieron en aquella parte del monte denominado "seco" provenían de familias que se habían establecido desde los siglos XV y XVI en las actuales provincias de Salta y Santiago del Estero. Éstos llegaron al Chaco noroccidental entre los siglos XIX y el XX (Dasso, 2010, p. 238) y en la literatura también han sido definidos como "chaqueños" (Montani, 2008). La presencia criolla no dejó indiferentes a los grupos wichís. Muchos empezaron a reorganizar sus actividades económicas prestando su fuerza de trabajo, de manera ocasional pero constante. Los wichís de Pompeya sufrieron la presencia criolla cuando los franciscanos abandonaron la Misión (a partir de 1949) y los que seguiron fueron años de violencia y sufrimiento (Franceschi, 2020) ${ }^{7}$.

John Palmer (2005, p. 28) recuerda el testimonio del wichí Federico Gauffin ${ }^{8}$ que utilizó en 1978 la palabra ahätäy para referirse a los criollos. Palmer traduce este apelativo como "los aparecidos" y le atribuye un doble significado: los que en un momento preciso "aparecieron" en el Chaco y "Ios fantasmas de los muertos". El criollaje es un tema que se reitera obstinadamente en todas las historias de vida wichís, pero es un tema marginal en historias marginales y poco compartidas incluso dentro de la misma comunidad.

El método biográfico y las historias de vida y de familia son un instrumento peculiar: utilizadas por parte de la antropología en su misión de "salvataje" de indigenistas, misioneros y educadores para obtener "almas individuales" (Calavia Sáez, 2007, p. 14), han producido historias cuyos resultados pueden parecer evasivos y ambiguos. Seguramente han permitido una mirada microscópica de un fenómeno, mostrando los ecos de tradiciones espurias, incómodas y que poco se ajustaban al canon sociocultural. En el contexto wichí, la historia de vida o la biografía es un género narrativo inexistente. Según la literatura, los dos géneros narrativos principales son los "mitos" o palhalis y los "casos" o pahchehen (Dasso, 1999, 2000). Los mitos tienen un contenido bien discernible: hablan de una creación de

\footnotetext{
7 El término "criollo" en la Argentina tiene un alcance histórico y designa distintas poblaciones según el contexto. En Misión Nueva Pompeya (un pueblo en una zona rural del interior, aún muy aislada) es utilizado con un significado "igualitario" (Schneider, 1998, p. 351) es decir, en su sentido más común, con todos los estereotipos y prejuicios que acarrea.

${ }^{8}$ Como aclara Palmer, se trata del hijo del escritor homónimo.

9 En el panorana norteamericano fue muy común trabajar con autobiografías durante el período posterior al Indian Removal Act (1830) que trasladó forzosamente las comunidades nativas al otro lado del Mississipi y la mayoría de las comunidades nativas terminaron viviendo en reservas. Fue en este momento que, antropólogos más o menos profesionales, comenzaron a recolectar autobiografías.
} 
seres animados e inanimados que en muchos casos asumieron (y asumen todavía) un valor trascendente, que engloba y absorbe los engranajes de una sociedad entera, $\mathrm{y}$, además, como dice Palmer, "la mitología wichí describe el mundo actual como una versión empobrecida del mundo idílico en que se vivía originalmente, que era una tierra sin mal" (2005, p. 37). Los "casos", por el contrario, no constituyen un género narrativo tan fácil de caracterizar: se trata, según Dasso, de "relatos del pasado" que abarcan desde "las circunstancias atravesadas por conocidos de conocidos hasta algunos relatos animalísticos percibidos como acontecidos en el tiempo mítico (2000, p. 330). Es decir, se interpretó que los casos son probablemente historias que trataban de explicar una realidad cercana a diferencia de los mismos que, aunque no necesariamente hablan de un tiempo lejano (Dasso 1999, pp. 50-52), hablan sí de metamorfosis que establecen un salto cualitativo, radicalmente distinto de la vida cotidiana. Realmente, no sé decir si la gente wichí me relató -recordando lo que escuchó de sus padres o abuelos- historias que son "casos". Esto quizás significa que la tradición y la continuidad de un género discursivo, su posible interrupción o transformación y las ocasiones comunicativas específicas en que se realiza son datos sensibles. En la literatura clásica sobre mitos y casos (Califano, 1999a, 1999b; Califano y Dasso, 1999; Dasso, 1999) estos datos no eran una parte que se compartía en la publicación. Por otro lado si hoy la fuente de mitos wichís mejor documentada desde el punto de vista sociocultural y lingüístico es la obra de Palmer (2005), es indudable que el universo indígena wichí muestra un conocimiento siempre renovado, en detalles y profundidad, de su propia historia y su cultura (Segovia, 1996 1998, 2005, 2011; Montani y Juárez, 2016; Dixon, 2014; Pérez et al., 2012), y que la autobiografía es un instrumento que los wichís parecían usar tanto para escribir u ordenar la historia local como para denunciar violencias de un pasado reciente (Franceschi (Ed.). 2008, 2018). En estas autobiografías afloran historias donde encuentran su lugar las misiones, el trabajo asalariado, la mecanización y su fracaso (Córdoba, Franceschi, Richard, 2020), la composición de una comunidad y de un pueblo; historias que la gente quiere recordar y que -sobre todole gusta contar. Los factores que han determinado la elección de la forma autobiográfica o autoetnográfica para narrar la historia local, una historia que termina siendo una épica -coral y legendaria-, son diversos y están todos relacionados: la escolarización y la evidencia de que hay cuestiones lingüísticas por resolver (como la ortografía y el alfabeto unificado); el uso de nuevas tecnologías y la creación de redes con otras comunidades indígenas; la aparición de escritores autóctonos cuyos libros empiezan a circular en las distintas aldeas; la formación de jóvenes universitarios wichís (Ossola 2015); los reclamos de tierras juntos a una nueva cartografía autóctona (Preci 2020; Scardozzi, 2015), una evangelización donde el testimonio es el elemento central para la conversión (Franceschi, 2017); el temor del olvido y de quedar olvidados, la voluntad de destacarse de un cierto tipo de criollaje para instituir sus propias subdivisiones interétnicas y, en fin, la conciencia de enfrentarse a un nuevo ciclo histórico que quieren y saben relatar. Eso significa también que los géneros narrativos en contexto indígena rápidamente van renovándose (Oakdale y Course, 2014) y plasman un tipo realmente autóctono de relato, que seguimos Ilamando autobiografía, pero que tiene características originales que concuerdan solo en parte con las de dicho género de la literatura occidental.

Al mismo tiempo, lo que se intenta en este artículo es proponer una "etnografía centrada en la persona", algo que es sumamente amplio y, a la vez, muy específico. Por un lado, estoy pensando en lo que propuso Michelle Rosaldo (1980, p. 262) cuando habló de una antropología de la persona que valoraba la acción humana sin estar implicada con el individualismo, el concepto de sí mismo (self-concept) o el de autoestima, que son todos dispositivos con un uso técnico preciso en la filosofía y la psicología occidentales. Una antropología de la persona y del sí (self) que describe la gente, que cuenta cómo habla e interpreta las formas simbólicas para sí misma y para su propia comunidad. Por otro lado, estoy pensando en una noción de "sí mismo" y de "persona" que queda, en todo caso, en la esfera de la "cultura", producto concreto de la vida social y de las reglas más o menos formalizadas que la moldean.

Para cumplir con estos objetivos, presentaré tres historias de vida. Son como fotografías instantáneas: relatos autobiográficos breves que registré en el campo, cada año, a partir del 2004. Son, a su vez, como las piezas de un mosaico, pues en conjunto componen una historia coral compartida. Cada relato tiene su evento clave, su acontecimiento, que es un "hecho social total". Condición esencial y, al mismo tiempo, instrumento "para estar en el mundo" -diría De Martino (1958)-, para entrar en la historia y no sucumbir. Teresa Juliet es una mujer "anciana" (algo que las mujeres han traducido con tres expresiones: hichut, taloj y wemek, este último término, con un sentido peyorativo y negativo), cuya familia participó de la construcción de los edificios de la Misión Nueva Pompeya (en adelante, Pompeya) y de la primera escuela, es decir, vio el nacimiento de esta comunidad wichí. Teresa cuenta su historia de la misión franciscana y se detiene sobre la importancia del trabajo y de las máquinas que trajeron los franciscanos. Otra mujer, Elena Calermo, más joven que Teresa, relata la fundación de la iglesia anglicana, que es el evento de su vida. Elena es una mujer que conoce bien los nombres de las parentelas (wichi Iheyis) de la zona; su esposo, que fue pastor de la primera iglesia anglicana del paraje Pozo del Toba, en 2004 me contó por primera vez, con determinación, los acontecimientos que anunciaron la llegada de la hermana Guillermina Hagen a Pompeya (Franceschi (Ed.). 2008) ${ }^{10}$. El

\footnotetext{
10 Guillermina Hagen Montés de Oca tenía el título de ingeniera
} 
marido le dejó a Elena como legado verba ${ }^{11}$ el pedido de seguir su camino como pastora anglicana, de estudiar, de cuidar la iglesia y no abandonarla. La última instantánea biográfica es la de Teodora Polo, una mujer de la misma generación que Elena, pero un poco más grande, que llegó a Pompeya hacia 1970. Su historia cuenta lo que significó vivir el cautiverio ${ }^{12}$, la horfandad y el criollaje. Teodora también expresa la importancia del trabajo: sus artefactos son su biografía interior, porque en el trabajo ella encuentra su satisfacción más plena y profunda. Su historia, con sus vicisitudes, es causa de enojos (täwäkäy), pero también es la que la capacitó para confrontarse conmigo y generalizar sobre algunos rasgos propios del universo wichí.

Durante nuestras conversaciones, estas mujeres wichís proponen ciertas palabras y se detienen en explicarlas. No siempre estas explicaciones coinciden con las que dan la literatura etnográfica o las gramáticas y diccionarios. Quiero aclarar, finalmente, que las mujeres en cuestión $-y$, en general, todos los wichís que escuché- quieren que sus relatos autobiográficos queden en forma escrita, en su propia lengua o en castellano, con fotografía, nombre y apellido, fecha y lugar donde fue contada la historia. La adherencia tan marcada por parte de estas mujeres respecto de las imágenes, la escritura y el nuevo saber tecnológico compartido, son elementos que debemos considerar, porque señalan una dirección muy clara: una trasparencia sensible y sin ambigüedad entre antropólogo y sus testigos.

\section{Lengua y palabra: la gente wichí de misión Nueva Pompeya}

Los conceptos locales de "lengua" y "palabra" son relevantes para los hablantes de cualquier idioma. Las palabras son depósitos -de ideas, conceptos y percepciones- donde se sedimenta el espíritu de una cultura. "Espíritu" quizás no sea el término correcto, pero

agrónoma y cuando llegó a Misión Nueva Pompeya era monja. Con la coordinación de la Dirección Provincial del Aborigen, el apoyo de las Hermanas del Niño de Jesús, la diócesis con Italo di Stefano y el Gobierno Provincial, armó una cooperativa de trabajo en Pompeya (1969-1973), cfr. Franceschi, 2021.

${ }^{11}$ Elena Calermo me habló de lëwitäle en una sola ocasión, para referirse al recuerdo y al testimonio que le dejó su esposo, que fue además una concretización de sus palabras y una especie de bendición a la futura iglesia anglicana del paraje. Sobre el lëwitäle, véase Palmer (2005, p. 212) y Montani (2017a, pp. 413-415).

12 Toskalej es la expresión que utilizó Teresa Juliet para hablar de la condición de cautiverio: "son los prisioneros, mujeres y niños eran presos por tribus con quienes se había conflicto; se llevaban mujeres y niños. Los varoncitos muchas veces los matan (14 de junio 2010). Las mujeres wichís criadas por familias criollas utilizan la palabra "cautivas" para describir su propia condición. Con el tiempo comprendí que los wichís habían "indigenizado" la palabra "cautivo" añadiéndole un significado preciso, el de una existencia en cierto modo no auténtica: "quebrada".

Se trataba también de una condición que indicaba un estado de reclusión. El cautivo era un naitsej, "atado", sin libertad de movimiento y privado de poder decisional. nos sirve para enunciar la complejidad y la estratificación que caracterizan a las palabras o, inclusive, a la lengua y la cultura. Lo que quiero decir es que las palabras son la primera carta de presentación de una lengua, y la más importante. En 1911 Boas atribuyó al pensamiento una relación privilegiada con la lengua, y fue Benjamin Lee Whorf-ingeniero químico, agente de seguros y lingüistael que hizo propia esta feliz intuición y se detuvo sobre la relación entre lengua y visión del mundo. Whorf creía que la estructura de cada lengua contiene en sí misma una teoría sobre la representación del entorno, una "metafísica", como la llamaba de vez en cuando. Escribía, por ejemplo:

Me parece gratuito asumir que un hopi que sólo conoce su propio idioma y la cultura de su sociedad tiene los mismos conceptos, a menudo considerados como intuiciones, de espacio y tiempo que nosotros tenemos y que generalmente se consideran universales. En particular, un hopi no tiene una noción general o intuición del tiempo como un continuo que fluye uniformemente y en el que todo el universo procede con igual velocidad, desde un futuro, a través de un presente, hacia un pasado; o en el que, para cambiar de punto de vista, el observador es arrastrado al flujo de la duración desde un pasado hacia un futuro. [...] Así, el lenguaje y la cultura hopi esconden una metafísica, al igual que nuestra concepción ingenua del espacio y del tiempo, o como la teoría de la relatividad; pero es una metafísica diferente de una y otra (Whorf, 1970, pp. 41-42).

Para Whorf, las configuraciones del lenguaje podían develar las características manifiestas (fenotipos) y latentes o implícitas (criptotipos) del pensamiento. La identificación de estas últimas es sumamente relevante, porque, "por un lado, muestra que las lenguas crean distinciones sobre lo que las palabras pueden hacer y sobre los que no hacen [...]; por otro, el hecho de evidenciar la existencia de criptotipos significaba también indicar que lenguas simples a nivel superficial (lenguas sin diferencias de género o número, por ejemplo) pueden ser muy complexas a nivel abstracto y latente" (Duranti, 2000, p. 62). Otra contribución fundamental sobre una "teoría de la palabra" se la debemos a Bronislaw Malinowski (1935), que insistió sobre la necesidad imperiosa de interpretar el papel que desempeñan las palabras en la vida social y sobre las constricciones de la interacción narrativa. Con estos autores, "la etnografía de la palabra, la teoría de los actos lingüísticos y el contexto lingüístico devienen parte de la etnografía moderna" (MonodBequelin, 2006, p. 626).

Las palabras son herramientas para clasificar nuestro ecosistema, para describir nuestra etnociencia y lo sobrenatural, para que nuestras experiencias encajen en las coordenadas espaciotemporales de nuestras vidas. Las palabras sirven para definir si el cuerpo está sano 
o enfermo, para representar nuestras percepciones y emociones. En fin, las palabras nos permiten mapear el territorio, nombrar los objetos, definir las relaciones sociales. Aunque, a su vez, no sea algo fácil definir eso que llamamos "palabra". Sapir sostuvo la imposibilidad de definir la palabra desde un punto de vista funcional, porque una palabra "puede ser todo, desde la expresión de un concepto -concreto, abstracto u relacional- hasta la expresión de un pensamiento completo" (1921, p. 32). Las palabras tienen sus características propias, que presentan en diversos grados: "tenemos palabras vacías -como decían los gramáticos de China- y más o menos 'llenas' o 'densas' y esto porque la relación entre sonido y sílaba, sílaba y morfema, morfema y palabra, palabra y frase cambia según el tipo de lengua" (Cuturi, 2010, p. 143). En suma, las palabras son dispositivos sensibles y debemos tenerlo en cuenta cuando nos toca manejarlas, transcribirlas, escucharlas.

En una lengua como la wichí (familia lingüística matacomaká), que es aglutinante y tiende a la polisíntesis, una única palabra puede ser traducida por toda una oración. Por lo tanto, al momento de definir que es una palabra y qué no lo es debemos tener en cuenta aspectos semánticos, gramaticales y fonológicos.

Las palabras wichís son estructuras complejas porque contienen información de distintos tipos: relaciones gramaticales de los participantes (a través de prefijos de los sujetos y sufijos de los objetos), tiempo y aspecto, negación, alteraciones de la valencia. Recuerdo bien mi primera visita a los wichís del Chaco argentino. Lo que más me impactó fue la alegría y la vivacidad lingüística ${ }^{13}$, algo que desentonaba abruptamente con el paisaje -un bosque que está siendo deforestado, un monte casi agonizante-y el tono emotivo de la gente -perfiles bajos, que bien podrían interpretarse como desanimados. En 2004, tenía fresca la lectura de un texto de María Cristina Dasso, donde la antropóloga argentina hablaba del poder que tiene la palabra entre los wichís:

La palabra surge como síntesis ostensible de lo que guarda el corazón, donde reside el alma o -husek, a la par que esta última entidad es vehículo para el contacto con los seres nohumanos que comparten el mundo con los wichí [...]. El mismo individuo manifestará su calidad personal a través de la elección de palabras suaves 'dulces', hlamet le kos o fuertes, estas últimas con frecuencia causantes de dolor y enfermedades. De hecho, inclusive la figura del 'reto verbal' es considerada con una gravedad difícil de advertir para quienes entablan contacto con los aborígenes [...] La palabra es para el individuo un medio que le permite, en ocasiones excepcionales, salvaguardarse, y en ocasiones cotidianas, manifestarse fuerte, entero, humano (1999, p. 48).

\footnotetext{
13 Según Censabella (2009), el 90\% de la población wichí sigue hablando el wichí como primera lengua.
}

Entre los wichís la palabra (/hämet) parecería ser algo que puede describir y suscribir -en el sentido de aprobar y comprobar - "estados" del alma o de la "voluntad" en la vida cotidiana o en lo trascendente, diríamos hoy siguiendo a Palmer (2005). La palabra es un instrumento capaz de expresar conceptos $u$ ideas que se materializan en artefactos o en una proxémica de la vida cotidiana (Montani, 2017a). La palabra, dice Rodrigo Montani, "en cierto sentido tiene el estatuto de 'cosa' y es la manifestación más inmediata del lëhusek de una persona" (2017, p. 414). Lo que Dasso escribió en 1999 reflejaba, por un lado, un contexto etnográfico preciso y, por el otro, una manera específica de conducir trabajo de campo. En la mayoría de las publicaciones de aquella época no se prestaba atención a la morfosintaxis o a las reglas gramaticales que hubieran ayudado a interpretar el significado de las palabras, pero -y esto es el puntola gente wichí con la que Dasso trabajó en los años 1980 y cuyos testimonios están en su libro de 1999, había conocido a través de sus padres los evangelios y el himnario en lengua wichí. Los wichís que se establecieron en la Misión Nueva Pompeya transitaban ya por el área, camino a los ingenios azucareros. Desde finales de 1800 habían empezado a escuchar el castellano de los criollos y los capataces que llegaban a la zona. Y cuando en 1910 el padre Rafael Gobelli quedó como encargado de la Misión, los niños empezaron a ser escolarizados en castellano. Los únicos wichís pompeyanos de esta generación que aprendieron a leer o escribir su propia lengua fueron los que iban a la provincia de Salta, exactamente con este objetivo. Conocí unos pocos, y todos pertenecían a la iglesia anglicana de Pozo del Toba, que hoy dirige Elena Calermo.

El fraile Gobelli cita en sus memorias la construcción de "un edificio que sirve para la escuela, es un rancho grande, como son todos los de las escuelas nacionales que funcionan en estos lugares" (1912, p. 45). El testimonio que nos dejó Gobelli es llamativo, porque da cuenta de que a pesar de -o, quizá, a causa de-su actividad y sus continuos compromisos, nunca aprendió la lengua wichí $^{14}$. Tempranamente, su ayudante en la escuela es un wichí educado en un colegio de Salta: Francisco Supaz (Gobelli, 1912, p. 65). En 1949 los frailes se fueron, abandonando la recién nacida comunidad. En la memoria de los wichís, los católicos no sólo llevaron instrumentos para poder trabajar, sino que también abrieron la primera escuela donde todas las noches se hacía "una instrucción moral y religiosa a los indios grande y chico [sic]" (Gobelli 1913, p. 65). Eran encuentros donde los frailes ejercitaban su misión educativa y los indígenas que ya había viajado a los colegios de Salta para instruirse, encontraron una ocasión para seguir aprendiendo castellano. Los futuros cacique de Pompeya (el mismo Francisco Supaz, entre otros) fueron todos hombres que sabían hablar castellano, mientras que el coraje (kapjwayaj) que había

\footnotetext{
${ }^{14}$ Los misioneros que se quedaron en Pompeya escribieron diarios, pero sólo se publicó el de Gobelli.
} 
caracterizado al líder tradicional (niyat) cuando "se ocupaba de guerras y conflictos [...] en la época de la Conquista del Desierto cuando había guerra con suwele y los grupos eran nómades" (Teresa Juliet, 1 de julio de 2006), ya se iba desvaneciendo.

En Pompeya, los frailes no utilizaron ninguna obra escrita en wichí y los wichís empezaron a conocer la Biblia y el himnario recién en la década de 1920, paulatinamente, en sus viajes a las misiones anglicanas de la provincia de Salta (Montani, 2017b, pp. 150-152). Los wichís cuidaron ( $t^{\prime}$ eya) la Misión cuando los franciscanos se fueron y el edificio quedó vacío, a partir de 1950. Lo hicieron como acto de agradecimiento para los misioneros, que habían sido "su escudo, su tapa, su protección (lep'ot en lengua wichí)" (Montani, 2020). Hoy, para los wichís de Pompeya, el edificio de la Misión es su "casa" (-wet), independientemente de su afiliación religiosa. Los hombres y mujeres que el fraile Gobelli recuerda en sus Memorias (1912, pp. 85-86) son los padres de los testigos que Cristina Dasso encontró en los años 1980, por ejemplo, Teresa Juliet.

\section{Teresa Juliet}

Teresa vive hoy en el paraje Cuatro Viviendas. Su padre era cocinero en la Misión y su abuelo, Ramón Musumé, trabajaba con una carreta "como chófer" -dijo Teresa cuando me contó la historia de la Misión. Su nieto, Fernando Topó, me la tradujo:

Ella hablaba que su padre era primero, que en la primera llegada de los franciscanos su padre siempre estaba con ellos como cocinero, siempre trabajaba con ellos. Cuando los franciscanos van hacia Salta llevaron a Angelito, se lo llevaron a Salta a conocer y estudiar; le enseñan a escribir, hablar en castellano. Después capacitaron [a los wichís] para [que fueran] carpinteros, no sólo [a] él sino [también a] otros jóvenes: David Chuteley, Francisco Supaz y también la jovencita Rosa Supaz se capacitó como auxiliar, para ayudar en la escuela. No sólo carpinteros [sino que los wichís también] hacían zapatos, collares, peines, [que] según dicen fabricaban con cueros de vacas, y los peines se hacían con distintos dibujos, por ejemplo, de pescado. Se llamaban "peines tsonis" porque tso viene de dientes, que ralla con los dientes, que puede peinar. David Chuteley era carpintero y mecánico. Ellos se capacitaron como representantes, delegados, coordinadores de los franciscanos, en idioma es lach'otfwas. Era una carga importante, era como un representante que tiene voto entre la comunidad. Estos representantes formaban grupos, como una ladrillería o sea después todos estaban en la ladrillería y empezaron a hacer la Misión. No sólo mi abuela habla de este trabajo; se hacían cercos, éstos eran trabajos que no se pagaban con plata sino con mercadería, tälhak [lit., "alimento de alguien"] [...] Teresa dice que vivían bien, todos tenían trabajo y tenían muchas cosas. Herramienta se dice lachumet-chalh [lit., "instrumentos de alguien"]. Cuando van hacia Salta trajeron animales, vacas, caballos y le hacían tipo cercos que cuidaba todos y con estos animales se le compartían entre las familias. Los animales ya tienen dueños y cada familia tenía sus animales. Trajeron vacas de raza mestiza y la repartieron, se hacía así. Cada dos años se recibía una vaca. Cada repartición era de un macho y una hembra así se podía tener su grupito de animales. [...] Pole Nom ya estaba habitado, ya había gente y estas familias sembraban trigo. $Y$ en esa época el franciscano iba de visita. $Y$ cuando ellos vieron los curas decían viene el cura y por eso ahora se llama "Laguna de los Curas". En esa época había un cacique que era Francisco Supaz en principio de la Misión [1900]. [...] La autoridad que tiene el cacique es que es la guía del pueblo, es el que me hace trabajar y trabajo-lachemet-abarca todo, actitud, poder, decidir, informar, ayudar y también defender. En esa época las familias todavía no hablan castellano y el cacique tenía autoridad y coraje, él transformaba y conocía los cantos de los pájaros y tenía kapjwayaj. La forma y la actitud del cacique es diferente en esa época. Antes era más difícil porque había conflictos entre grupos, eran grupos vagabundos, grupos de familias que se movían y había grupos que se peleaban entre si y había guerra con suwele y con tseku [...]. Y en esa época había un cacique ${ }^{15}$ que cuando le disparaban una pelotita de barro no le hacían nada. Como si su cuerpo fuera cubierto de barro. Come si el cuerpo había una coraza. Después no hubo más estas personas [...] pero hay que nombrar los caciques. Chuteley, Chiripa, Supaz. Para hacer la historia. Los que se fueron con los franciscanos. Hay que escribir lo que hicieron. Ellos cuando trabajaban con los curas iban a buscar mercadería, a Metán, Tucumán, Orán. Cruzaban el río con el carro. Chuteley, Manik, Ramón, Chiripa ${ }^{16}$, Supaz era un grupo que trabajaba con los misioneros como ayudantes. La gente criaba, sembraba (Teresa Juliet, 1 de julio de 2006).

Tanto Teresa como su esposo, Heriberto, pertenece a familias wichís que se instalaron en Pompeya a principio del siglo XX. Según Teresa, ya había wichís que vivían en lo que hoy es el paraje Pole Nom -pole significa "pelado" y, por metonimia de la tonsura, "cura", y nom o näm, "llega", "viene", o sea que pole näm es tanto "viene el pelado" como "llega el cura", aunque hoy el topónimo se traduce como "Laguna de los Curas". Como Heriberto dijo en varias ocasiones, los Carrizo pertenecenen a las parentelas denominadas kalentajitaj (una avispa grande). Los padres de Teresa se habían comprometido desde el

\footnotetext{
15 Debe tratarse del cacique Mulato que también recuerdan otros wichís y que es mencionado por Fontana (1881, p. 101), Pelleschi (1881, p. 60) y Gobelli (1912, p. 91)

${ }^{16}$ Chiripa fue cacique entre 1930-1940.
} 
comienzo en aprender castellano con los frailes. Se trataba de gente que había estado trabajando en los ingenios y que, especialmente en esta área, cuando terminó el auge del azúcar, continuaron trabajando estacionalmente en los campos de algodón de la colonia Juan José Castelli. Teresa y su familia estuvieron entre los primeros habitantes de Pompeya. Teresa se casó en Castelli, bajo el rito católico, durante una temporada de cosecha. La familia de Heriberto venía de Fortín Arenal, como también de allí otras de Pompeya. Ellos conocían la vía del tren y para llegar a Pompeya pasaban por Comandacia Frías, que recuerdan como "el camino de la caña dulce". La familia se trasladaba para cosechar y se quedaba viviendo allí durante la morada de trabajo.

Mientras Teresa relataba su historia, la acompañaba su nieto Fernando, que es un joven maestro. Teresa estaba sentada y sus ojos estaban siempre mirando al nieto. Con su voz tan baja, el mismo Fernando le preguntaba frecuentemente de repetir y a pesar de su avanzada edad, ella estaba segura de sus palabras y las preguntas casi la molestaban. Con el nieto buscaron una etimología para tsonis, "peine": viene de tso, que "viene de dientes", tsotey, porque "se ralla con los dientes". Los peines eran de madera, y cuando reescuchamos la entrevista Teresa agregó "los peines se hacían con dibujos por ejemplo de pescado", me pidió el bolígrafo para dibujar un pez que en su parte anterior tenía un peine ${ }^{17}$.

Una buena parte del relato de Teresa está dedicada al tema del trabajo. Habla de lach'otfwas, que significa "apoyo", "cuña" y deriva del verbo -ch'ot (ayudar, sostener). Esta vez, ni la abuela ni el nieto buscan la etimología, pero comentan que läch'otfwas eran como "representantes y coordinadores, una carga importante como alguien que tiene un voto". Los misioneros son recordados por el trabajo, las herramientas y los oficios que enseñaron. A partir de este momento el trabajo asume una connotación ética clara y los wichís se especializan en oficios que en su mayoría siguen practicando hasta hoy. Teresa también menciona unos gentilicios muy comunes en Pompeya y en otras zonas del territorio wichí: suwele, que hoy nombra a los criollos pero que, originalmente, nombraba a los chiriguanos, enemigos históricos de los wichís occidentales (Montani, 2017a, p. 80); tsekhu ${ }^{18}$, que se aplica a los "gringos de afuera", "los gringos con ojos azules", los que tienen "pinta blanca" (de hecho, Teresa dio como ejemplo "Zelda es tsekhu pelah", es decir, "gringa blanca") y, finalmente, waj-chäs, que nombra a los anglicanos ("Es la historia de los anglicanos y también hay otra palabra que es waj-chäs y que significa 'gente de mar', 'gente extranjera'") $)^{19}$. La diferencia entre suwele y tsekhu parece radicada en la proveniencia endógena

\footnotetext{
${ }^{17}$ Este dibujo recuerda la imagen n. 76 de Boggiani, 1895, p. 160

${ }^{18}$ No sé si se trata de sekw, aféresis de isekw o isukw, 'tonto', 'loco'.

${ }^{19}$ Makower (1989, p. 13) en su libro define los anglicanos como "Ios blancos que vienen del mar". Waj-chäs, lit. significa "cola de agua" que puede ser "el último que viene del mar" (Montani, 2017, p. 82).
}

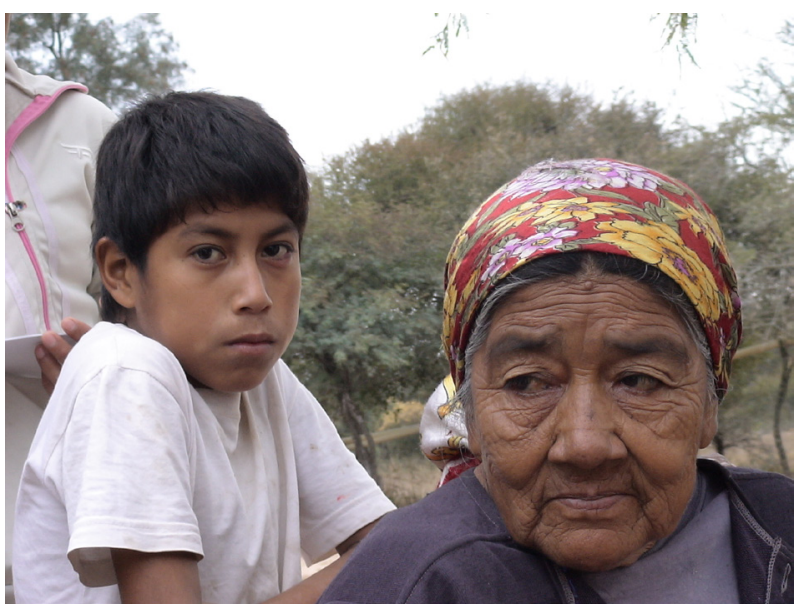

Figura 1. Teresa Juliet en su casa, el Paraje Cuatro Viviendas, Misión Nueva Pompeya (Chaco-Argentina). Fotografía de la autora. Julio 2008

Figure 1. Teresa Juliet in her house, Paraje Cuatro Viviendas, Misión Nueva Pompeya (Chaco-Argentina). Photograph by the author. July 2008.

(suwele son los criollos o blancos de la Argentina o del Chaco) y exógena (tsekhu es gente que viene de lejos, extranjera) y es algo que nos confirma que no todos los otros son iguales, no todos tienen las mismas connotaciones y características.

\section{Elena Calermo}

Teresa fue madrina de bautismo de Elena Calermo. Se trata de un vínculo renovado por distintas alianzas matrimoniales. Elena vive en el paraje Pozo del Toba y cuando le pregunté por el nombre de su parentela me dijo wänlhäy, es decir, "toba". En otra ocasión dijo que el nombre de su parentela es pekletaj, que tradujo como "pescadito"20. La familia de Elena vivía en Lanchetaj (de lanek, "ostra21", "las conchas del río")22. En 2017, mientras estaba en su casa, Elena me comentó que todavía nadie había escrito la historia de la iglesia anglicana del paraje: no tenía "su escritura" (lelesaynyey) ni su libro (lib/u), quería contármela, respondiendo al pedido que le había dejado su finado esposo.

La iglesia anglicana falta de un libro porque nosotros a veces queremos festejar el cumpleaños de la iglesia y ahora queremos hacer fiesta el 17 de diciembre. Quiero decirte cuándo empezó la iglesia. Primero había un hombre que se llamaba Pedro Torres y el siempre salía de Ingeniero Juárez y Pozo Yacaré y ese hombre tenía una iglesia en San Isidro y con su padre

\footnotetext{
${ }^{20}$ Como vemos, en mis datos a veces no está claro el límite entre los nombres de parentelas wichís y los etnónimos que los wichís dan a los grupos indígenas vecinos; el caracter un tanto difuso entre ambas categorías (nombres de parentelas wichís y etnónimos) también fue observado por Montani y Combès, 2018.

${ }^{21}$ Así dijo Elena Calermo.

22 "Valva de la gran almeja del río", según Montani, 2017a, p. 290.
} 
Eusebio Nucos. La familia de Eusebio estaba acá y el padre de mi marido, Miguel Azarte tiene un hijo mayor que se llama Felix y otro que se llama Simón. Y ellos siempre se van por allá para escuchar la palabra del Señor. Y ellos la trajeron y empezaba y empezaba y quería tener la gente para empezar la iglesia y los otros que venían por acá y que viven por acá, era poca gente, pero iban a escucharlo y tenía una sola Biblia. Antes los miembros no tenían nada y enseñaban la palabra de Dios para cantar, orar y todo eso. Y eso era católico y se podía hacer bautismo también. Después ha venido acá una misionera no me acuerdo bien creo que en 1964 [...] se llamaba Luisa y vienen por acá y atraversaba el río [Bermejito] y ya no tiene con qué venirse y dice que encontraba un maestro que tiene un carro que usaba con un solo caballito o burrito y le han prestado el carrito y viene para acá y se juntaba con la gente y le sacaba foto y ahí empezaba a levantar la iglesia y toda la gente que vive allá en Pompeya viene para acá. Ahora se trata de gente grande, Teresa Juliet, la familia de Teresa viene para acá a escuchar y le gustaba y yo tenía 12 o 13 años. Yo iba a la iglesia y me gustaba cantar y enseñar y ese hombre que se llamaba Simón enseñaba oraciones y cánticos y palabras y allá yo aprendí. Antes yo no sabía nada porque no iba a la escuela porque quedaba muy lejo de Lanchetaj; y entro a la iglesia y me enseñaron a leer. Lo que no me queda es escribir. Aprendí en la iglesia a leer cánticos en castellano y en wichí. En aquel tiempo no había nada solo la religión de la iglesia anglicana y después la gente se fue a cosechar en Castelli y quedaba en la iglesia la finadita Carmen, la esposa de Dionisio Matorras. Ella cuidaba la iglesia y cuando llegaban de la cosecha le llevaban cositas para ella como zapatillas, ropas, telas para hacer vestidos. Y después se levantó la iglesia y nosotros ayudabamos a traer agua para hacer barro y un palo pico como esto; todo el techo estaba de tierra y la gente escuchando la palabra de Dios aprendía. Levantamos la iglesia y a ellos no le gustaba vivir lejos porque falta agua y así nos venimos para acá y los misioneres nos ayudaron para levantar la iglesia de material y despues el finadito Simón habla con un doctor de Castelli que se Ilama Sotelo y él dice que nos van a ayudar y hace nota por el trabajo y el gobierno. Ese hombre llegaba a la iglesia pero yo todavía estoy soltera, y le llevaron el acta para tener trabajo en Pompeya porque todos se van a Castelli y en otro lado porque no hay trabajo y la gente sufre. Lo que hacíamos es ir al monte buscando miel y animales para cazar y antes no compraban artesanía y nosotros hacemos logrando así. El gobierno dice que nos va ayudar y la gente regresa de Castelli y hay los dirigentes hay que buscar 200 hombres que van a Tres Isletas para llevar la nota que tenía, y vienen tres misioneros. Antonio Polo, Augustin Tuisek con Simón son tres hombres Antonio
Polo con Clementina que tenía tres años llevaba para mostrarla allá y en Tres Isletas hay hombres que trabajan en dirección aborígenes y dice que ese hombre hace todo y dice que va a mandar gente y cuando nosotros llegamos para acá en dos semana llega la Guillermina y se limpia todo que era lleno de mugre, de basura y limpiaba todo, la gente trae mercadería y la gente vuelve de nuevo porque había trabajo (Elena Calermo, 13 de septiembre de 2017).

La fundación de la iglesia anglicana en Misión Nueva Pompeya fue particular, porque no hubo una permanencia estable de los anglicanos en el lugar, sino que algunos wichís de Nueva Pompeya, como el padre de Avelino y su hermano, fueron a conocer a los anglicanos instalados en las cercanías (Franceschi, 2018). A partir de la década de 1960, los anglicanos comenzaron a organizar desde las misiones de Misión Chaqueña, San Patricio, La Paz, Ingeniero Juárez, visitas a las comunidades más alejadas. En vez de enviar misioneros de forma permanente, planificaron cursos para los indígenas de las futuras iglesias, entre ellos, los wichís de la zona de Pompeya (Makower, 1989, p. 135). Es cierto que algunos wichís de Pompeya ya conocían a los anglicanos, porque habían vivido con ellos temporadas breves en algunas misiones (en particular, Misión Chaqueña) ${ }^{23}$, donde habían aprendido a leer y escribir en su propia lengua.

Elena nació en aquel entonces, y a los 10 o 13 años ya frecuentaba la iglesia anglicana. El 1965 fue un año azotado por la sequía: mucha gente de Pompeya recuerda que "la cosecha no daba y nosotros vimos que no había nada y comprendimos que por el bien de la comunidad necesitabamos ayuda, la gente no podía comprar, un fracaso" (Francisco Matorras, 15 de septiembre 2019). Fue entonces que Dionisio Matorras, Simón Lazarte y Laureano Polo se fueron a Resistencia para hablar con el gobernador (Franceschi, 2018).

El relato de Elena es la última pieza de una larga serie. Su difunto esposo, Avelino Lazarte, comenzó en 2004 a compartir la historia de lo que pasó en Pompeya a partir de 1960, y seguieron el también difunto Dionisio Matorras, su hermano Francisco, Sabino Polé, Abehildo Yayis y mujeres como la fallecida Argentina Polo, Elda Argañaraz, Elena Calermo. Simón fue el responsable de una acción política importante. Como muchos caciques que creían en las promesas del presidente Juan D. Perón y que participaron activamente del nuevo gobierno populista con la esperanza de obtener asistencia y ayuda, Simón Lazarte envió petitorios a las autoridades provinciales. En respuesta, recibió instrumentos agrícolas, semillas, alimentos y nuevas escuelas. En aquel entonces los contingentes indígenas

\footnotetext{
${ }^{23}$ Esta misión, ubicada a 40 km. de Embarcación, cerca del río Bermejo, también fue conocida como "Algarrobal" y fue "el centro axial de la acción anglicana y piedra fundamental desde donde salen los misioneros para abrir las nuevas estaciones" (Córdoba, 2020, p. 41).
} 


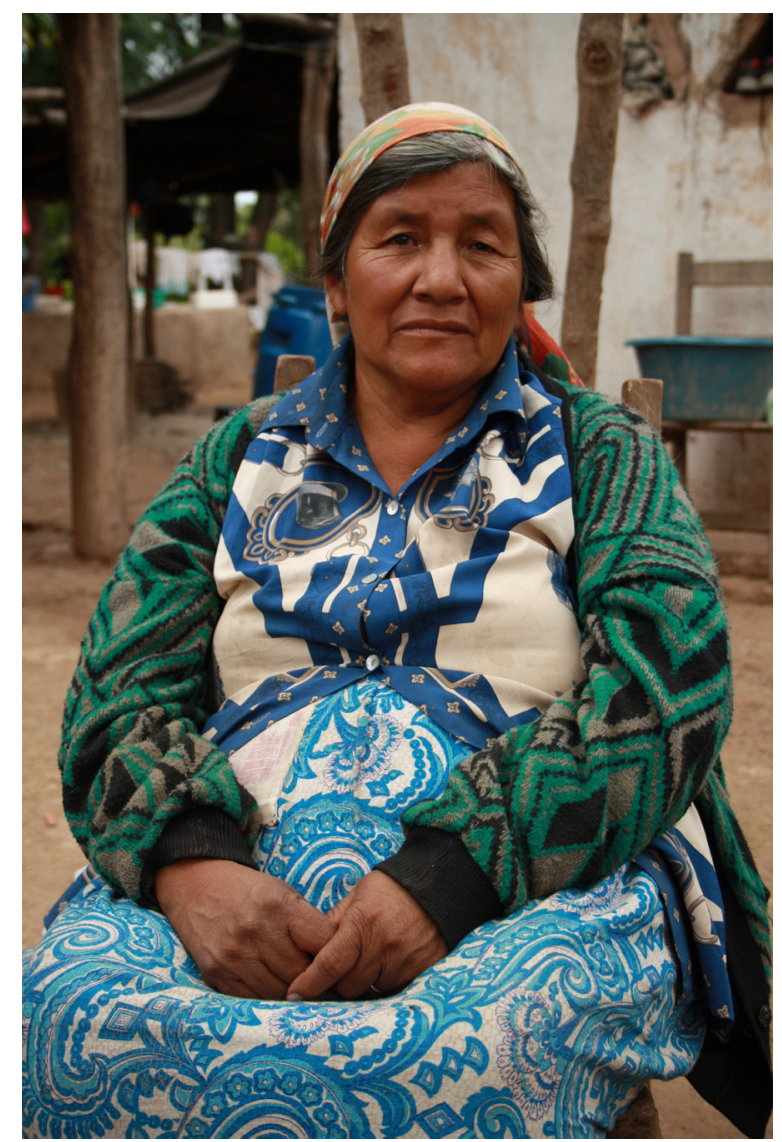

Figura 2. Elena Calermo en su casa, el paraje Toba, Misión Nueva Pompeya (Chaco-Argentina). Fotografía de Clio Corradi. Junio 2010.

Figure 2. Elena Calermo in her house, Paraje Toba, Misión Nueva Pompeya (Chaco-Argentina). Photograph by Clio Corradi. June 2010

fueron un elemento fundamental para el futuro de las nuevas comunidades porque, "constantes fueron los pedidos a cargo de un jefe y lenguaraz [indígena] los que llevaron los misioneros a inaugurar otro emplazamiento" (Ceriani Cernadas y López, 2017, p. 30). Y en Pompeya pasó esto: la empresa de Simón Lazarte llevó a la Misión la hermana Guillermina Hagen, inaugurando una nueva e inolvidable página de la historia wichí. En el medio de todo esto, Elena pone el surgimiento de la iglesia anglicana, su construcción y su historia. No es tanto la historia en sí que me parece de interés, cuanto el hecho de haberla contado en castellano, como hizo su esposo, y pidiendo insistentemente su versión escrita para que quede en la comunidad. Al margen, en la historia llama la atención la mención de dos mujeres: Carmen Lazarte, que cuidó la Misión durante el tiempo de la cosecha, y el de una misionera, Luisa, que llegaba para enseñar el nuevo credo anglicano.

\section{Teodora Polo}

Teodora tiene unos 75 años, habla wichí y comprende el castellano. No frecuentó ninguna escuela, no sabe leer ni escribir. Cuando empezó a contarme su historia, la palabra que utilizó fue la misma que aplicaba a su trabajo: ipätsin, un verbo que indica principalmente la actividad femenina. En la historia de Teodora, el trabajo (lachemet) tiene un papel fundamental y ella fue capaz de contarme su historia mientras estaba trabajando. La familia Polo es según ella chom-Iheley, "abajeños", de la banda sur del Bermejo; son de la parentela de los awutsas, que ella tradujo como "chancho negro del monte". Hoy vive con su familia en el paraje Araujo, que en wichí se llama Kastak-Ihiley, "hueso de pescadito o planta que crece en los charcos", tradujo Teodora. Es de la misma familia que Elena Calermo. La madre de Elena Calermo, Elena Polo, es una hermana mayor del padre de Teodora, Eduardo Polo. Para reconstruir la historia de vida de Teodora, Elena Calermo fue siempre generosa y precisa. Las une un destino común a muchos wichís: son "criadas", es decir, Elena por una mujer wichí y Teodora por criollos. Las une también el formar parte del mundo criollo. Así lo comentaba Elena:

\begin{abstract}
Me fui hace un año a Rivadavia Chañaral (Salta) y allí encontré un hombre de la familia Polo y todos son de más criollos. La pinta. Y hablan wichí. La pinta era así de mi abuelo Eduardo Polo que era como criollo, un poco blanco y rubio. Mi mamita también y por eso me dicen que mi cara es más blanquita. Y cuando hablan castellano y wichí mezclan palabras. Eso era y no sé como será. La mamá de mi mamá hablaba mezclando las palabras y los nietos también. Y es por eso que nosotros entendemos el castellano porque así era mi abuela y me enseñaba castellano. Son mezcla, mestizo con blanco, siwele (Elena Calermo, 7 de septiembre 2017).
\end{abstract}

Teodora fue criada por sus abuelos y por una familia criolla. Su madre, abandonada por su marido, no pudo ocuparse de su hija y se la confió a sus padres. Estos abuelos de Teodora, repite ella muchas veces, le "mezquinaban todo" ( $n^{\prime}$ äyej), y cuando ella tenía entre 8 y 10 años, ellos la confiaron a su vez a una familia criolla, que se ocupó de ella y la crió. Con ellos, Teodora se acostumbró al trabajo criollo, empezó hablando aprendiendo un léxico prestado a los chaqueños que le permitió tener vínculos estrechos con todos los criollos campesinos que encontró en su camino. Conoció el mundo criollo, lo apreció y despreció al mismo tiempo. La verdad que aflora en su historia es que hay gente wichí que conoció y frecuentó el mundo criollo desde adentro y en profundidad, un mundo con el que los wichís comparte y disputa, sobre todo, recursos económicos. En la historia de Teodora el mundo criollo es violencia y matrimonio, robo de tierra y trabajo, discriminación, abuso y, de nuevo, matrimonio. Las palabras de Teodora manifiestan una crueldad casi resiliente que ella ha sufrido por parte de la gente wichí de su aldea. Una vez más, no sé si utilizo la palabra correcta, pero es la que más se acerca a una actitud que muestra sufrimiento, resistencia y sobre todo buena voluntad 
para seguir siendo "wichí" en su sentido más pleno, es decir, el de "humano". La existencia de Teodora entre mundo indígena y criollo era un pretexto para que sus vecinas, sus parientes más cercanos y la gente (no solo indígena) comentara conductas que se consideraban inapropiadas y que ella traducía con un sentimiento que en otras ocasiones había revelado cierto malestar, pero también temor (nowaya). No se llegaba a la "maldición"24, pero su intensa labor de artesana era siempre motivo de chismes y cotilleos. Teodora -y con ella muchas mujeres wichís cuyo destino fue un precoz y duro contacto con los criollos- queda al margen de una sociedad indígena que la marginaliza. Como resultado de esa experiencia le queda quizás su capacidad de hablar un incierto dialecto wichí del castellano; su perfil social y su manera de trabajar, y también su genuino deseo de ser wichí, de un modo sospechoso y algo inconforme. Teodora Polo, un poco Elena Calermo y un poco menos Argentina Polo, tía de Teodora y partera reconocida de Pompeya, toda ellas son mujeres que tienen esta marca criolla, que en parte se disipa porque han sabido seguir hablando su lengua wichí y armar alianzas matrimoniales con wichís, pero una marca que se refuerza por su búsqueda de un buen manejo del castellano. A pesar de que trabajé con Teodora durante varios años, en uno de nuestros últimos encuentros me dijo algo por primera vez:

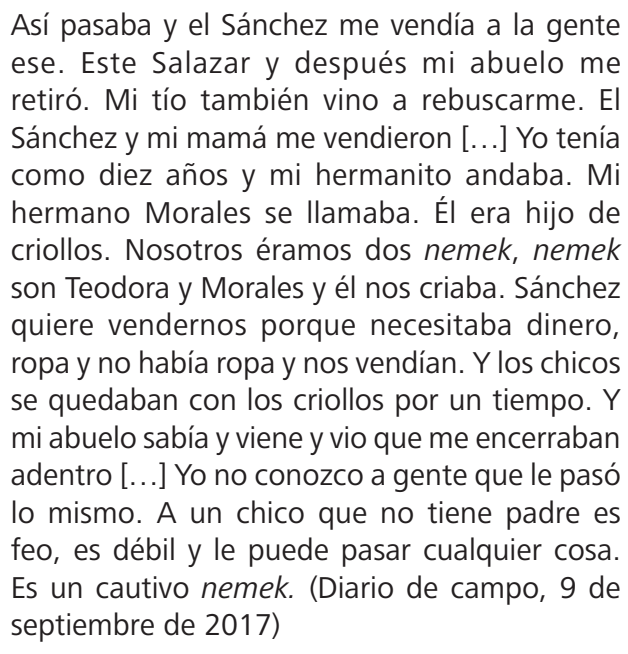

Hay varias palabras recurrentes en la historia de Teodora. En primer lugar, el "mezquinar" (n'äyej) de sus abuelos, algo que ella transforma y reinterpreta continuamante intentando que aparezca algo "bueno". Porque en el mundo tradicional la mezquindad solo tiene connotaciones negativas: el mezquino es simplemente malo y lo que hace es feo; "mezquino" es sinónimo de "tacaño" (tsofwnaj) (Franceschi, 2019, pp. 3-4). Para Teodora, la mezquinidad de sus abuelos deviene una actitud para protegerla, cuidarla y controlar que no le pasara nada. En segundo lugar, nemek, que Teodora traduce por el

\footnotetext{
${ }^{24}$ Teodora habla de enojo también que traduce con la palabra wichí, täwäj. Su comportamiento despierta suspicacias, chismes que pueden llevar incluso al disgusto, a la rabia de sus vecinas o a las habladurías de todo el pueblo.
}

sustantivo "huérfano". En la visión de Teodora, nemek tiene atributos que lo acercan a la pobreza (palitsaj) y al abandono (wemek), usada por las personas ancianas "rechazadas", "descartadas" y "abandonadas", y que indica la condición de huérfano. El rechazo que implica para Teodora la condición de huérfano se cifra en la falta de reconocimiento por parte del padre; esto producía incomodidad y vergüenza. Era una situación que no podía ser reparada. Tanto en el caso específico de Teodora como en el de muchos niños y niñas wichís, queda claro que en una sociedad donde la matrilocalidad sigue siendo una regla, el no reconocimiento de un padre condensa el temor a que éste sea un criollo y que la condición de la persona sea, por tanto, la de un "cruzado". Pero la lógica puede percibirse como positiva también y se encuentra en la covada, es decir, en la conducta del padre antes y después el parto. "El padre acompaña y le pasa al bebé su sangre. Y pocos días antes de que nazca el bebé hay una prevención con el padre, el padre tiene que quedarse quieto, sentado porque todo lo que puede hacer puede dañar el bebé" (Argentina Polo, 9 de julio de 2005). Es el padre quien trasmite simbólicamente, o mejor dicho metafísicamente y de manera trascendente, verdor y vitalidad a su hijo, "la noción wichí de la transmisión

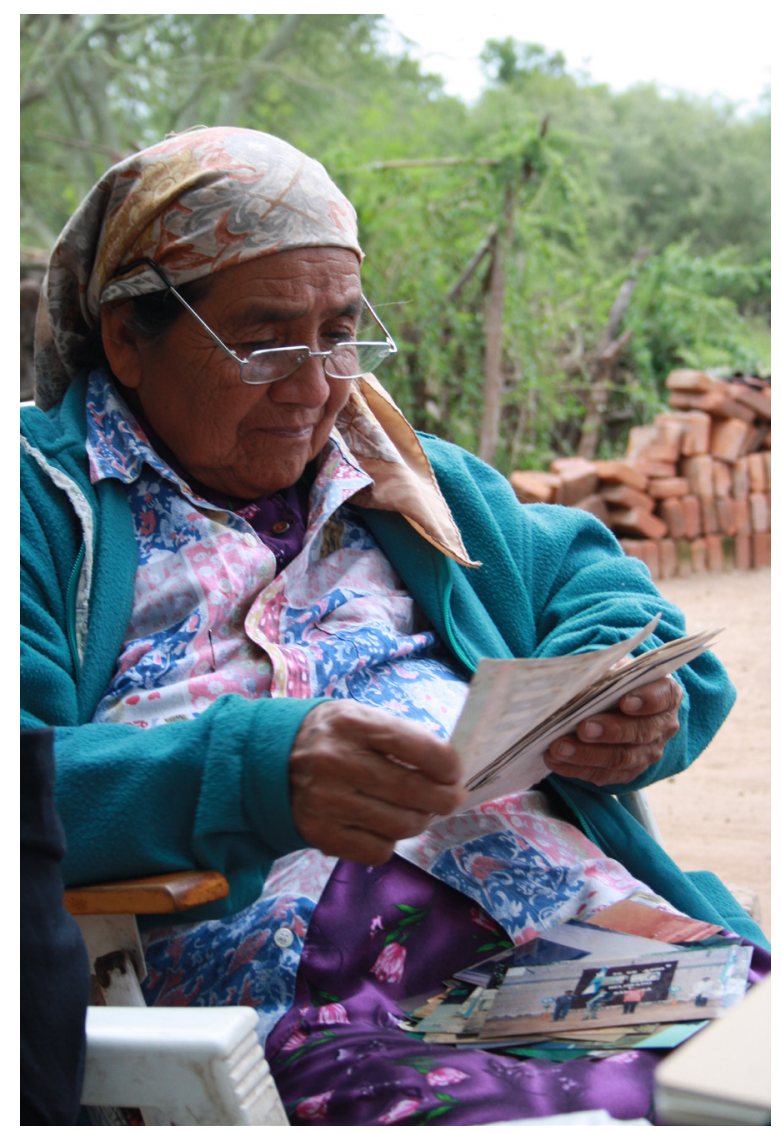

Figura 3. Teodora Polo en su casa, el paraje Araujo, Misión Nueva Pompeya (Chaco-Argentina). Fotografía de Clio Corradi.

Figure 3. Teodora Polo in her house, Paraje Araujo, Misión Nueva Pompeya (Chaco-Argentina). Photograph by Clio Corradi. 
paterna de sangre al feto es un correlato de su teoría patrilinear de la concepción" (Palmer, 2005, p. 191). Todo eso resulta de una claridad que provoca desconcierto en el relato de Teodora, que no es hija del cacique Eduardo Polo ni conoce a su padre criollo.

\section{Palabras finales}

Vi a Teresa, Elena y Teodora riéndose mucho con sus nietos. Cada vez que regresaba al Chaco, en la casa de una o de otra encontraba siempre nuevos jóvenes, nietos o criados que se quedaban a vivir por un tiempo. Ví también la preocupación por muertes precoces, por enfermedades que podrían haberse curado, por jóvenes que no encontraban su destino. Las mujeres se sentían frágiles y me decían que estaban preocupadas. Utilizaban una palabra, tichun/hi que se podría traducir como "pensar", "añorar" o "recordar". El pensar es un verbo que introduce una acción que requiere un tiempo para reflexionar, algo que se sitúa entre la reflexión y el pensamiento (letichunhayaj) es un estado de ánimo que no permite vivir con tranquilidad (letamsek). La reflexión sobre su propia historia y sus vivencias, con los franciscanos, aprendiendo el credo anglicano, con Guillermina, trabajando con los criollos y los chaqueños, es algo llamativo. No sé si estos fragmentos de biografías son un nuevo género, un género que recuerda -al menos en parte- el de la autobiografía, o si es más bien el resultado del influjo del "dar testimonio" que forma parte del rito de las distintas iglesias (la anglicana, pero sobre todo de la evangelista Iglesia Unida), tampoco puedo decir si estas mujeres eligieron el castellano para que los argentinos -antropólogo mediante-conozcan su historia. Me parece que se trata ante todo de una reflexión sobre una experiencia; una experiencia que Teresa, Elena y Teodora han querido compartir conmigo, para que pueda comprender y aprender lo que fue la vida de ellas, una vida de trabajos y aprendizajes.

\section{Agradecimientos}

Quiero agradecer a los wichís, hombres y mujeres que en los años me ayudaron y siempre me han acogido en sus casas. A Rodrigo Montani, Lorena Córdoba y Diego Villar por sus aportes constructivos y su generosa paciencia.

\section{Bibliografía}

Bateson, G. (1988 [1936]). Naven. Un rituale di travestimento in Nuova Guinea. Turín: Einaudi.

Berman, J. (1996). The Culture as It Appears to the Indian Himself: Boas, George Hunt, and the Method of Ethnography. En Stocking, G. W. Jr. (Ed.). Volksgeist as Method and Ethic. Essays on Boasian Ethnography and the German Anthropological tradition, History of Anthropology, vol. 8. Madison: The University of Wisconsin Press, 215-255.
Boas, F. (1911). Introduction. En Handbookof American Indian Languages. Washington: Smithsonian Institution Press, 1-83.

Boas, F. (1940). Race, Language and Culture. Nueva York: Macmillan.

Boggiani, G. (1895). I Caduvei (Mabayá o Guaycurú). Roma: Ermanno Loescher \& Co.

Bórmida, M. (2003). Etnología y fenomenología, Archivos, $X, 205-233$.

Calavia Sáez, O. (2006). Autobiografia e sujeto histórico indígena. Novos Estudios, 76, 179-195.

Califano, M. (1999a) (Ed.). Mito, guerra y venganza entre los wichí. Buenos Aires: Ciudad Argentina.

Califano, M. (1999b). Paradigmas ético jurídicos del ciclo de las teofanías vengadoras de los mataco. En M. Califano (Ed.), Mito, guerra y venganza entre los wichí. Buenos Aires: Ciudad Argentina, 55-144.

Califano, M., Dasso, M. C. (1999) (Eds.). El chamán wichí. Buenos Aires: Ciudad Argenina.

Ceriani Cernadas, C., Lopéz A., (2017). Los evangelios chaqueños. Misiones y estrategía indígenas en el siglo $X X$. Buenos Aires: Rumbo Sur.

Campbell, D. T., Levine R. A. (1970). Field-Manual Anthropology. En Cohen R., Naroll R. (Eds.). A Handbook of Method in Cultural Anthropology. Nueva York: Columbia University Press. 366-387.

Censabella, M. (2009). Atlas sociolingüístico de pueblos indígenas en América Latina, t. I. Cochabamba: Fondo de las Naciones Unidas para la Infancia/Fundación para la Educación en Contextos de Multilingüismo y Pluriculturalidad-Andes.

Cuturi, F. 2010. Parole. En Pennacini C. (Ed.). La ricerca sul campo in antropologia. Oggetti e metodi. Roma: Carocci, 125-180.

Darnell, R. (2001). Invisible Genealogies: A History of Americanist Anthropology. Lincoln: University of Nebraska Press.

Dasso, M. C. (1999). La máscara cultural. Buenos Aires: Ciudad Argentina.

Dasso, M. C. (2000). Ritualizaciones narrativas entre los wichí. En Bequeline M., Erikson P., (Eds.). Les rituels du dialogue. Nanterre: Société d'ethnologie, 329-345.

Dasso, M.C. (2010). Memorias y representaciones sobre 
el criollo del Chaco argentino. Confluenze, 2, 236- 253.

De Martino, E. (1975 [1958]). Morte e pianto rituale nel mondo antico. Túrin: Bollati Boringhieri.

Dixon, Á. (2014). Imak tä ihi p'ante honhat tä Ihey Mola Lhathi/Historias de "Bebedero de la Mula". Salta: ASOCIANA.

De Mauro, T. (2002). Capire le parole. Roma-Bari: Laterza.

Duranti, A. (2000). Antropologia del linguaggio. Roma: Meltemi.

Fontana, L. J. (1977 [1881]). El Gran Chaco. Buenos Aires: Solar Hachette.

Franceschi, Z. A. (2021). Un siglo de misiones: trabajo y máquinas en el monte chaqueño con los wichís de la Misión Nueva Pompeya. En Richard, N., Franceschi, Z. A., Córdoba, L., (Eds.). La misión de la máquina. Técnica, Extractivismo y Conversión en las Tierras Bajas Sudamericanas. Bolonia: BUP.

Franceschi, Z. A. (2019). Emociones y significado en la autobiografía indigena: reflexiones a partir de un caso wichí (Gran Chaco). Disparidades, 74 (1), 1-7.

Franceschi, Z. A. (2018). Tessere storie. Etnografia nel Chaco argentino. Bolonia: Emil.

Franceschi, Z. A. (2017). Testimonios as Autobiography. Daily Life and Beliefs among the Wichi in the Argentine Chaco. En Destro M., Pesce M., (Ed.). Texts, Practices, and Groups. Turnhout: Brepols, 577-613.

Franceschi, Z. A. (Ed.) (2008). Etnografia. La scrittura come testimonianza tra $i$ wichí del Chaco argentino. Bolonia: Emil.

Gobelli, R. (1912). Memorias de mi prefectura y apuntes sobre el Chaco (primera parte) Salta: Imprenta y Librería De Tula y Sanmillán.

Gobelli, R. (1913). Memorias de mi prefectura y apuntes sobre el Chaco (segunda parte) Salta: Imprenta y Librería De Tula y Sanmillán.

Gobelli, R. (1914). Breve estudio etnográfico sobre la tribu Mataca. Memorias de mi prefectura y apuntes sobre el Chaco. En Apuntes sobre el Chaco. Parte III. Salta: Imprenta y Librería De Tula y Sanmillán.

Makower, C. (1989). Don't Cry for Me. London: Hodder and Stoughton.

Malinowski, B., (1935). Coral Gardens and their magic. Londres: Allen \& Unwin.
Mauss, M. (1965 [1938]). Teoria generale della magia e Itri saggi. Turín: Einaudi.

Mauss, M. (1947). Manuel d'Ethnographie. París: Payot.

Millán, M. D. (1959). Vestimenta y Adorno. En Imbelloni J. et al. Folklore argentino. Buenos Aires: Editorial Nova, 287-333.

Monod-Bequelin, M. A. (2000). Parola. En Bonte, P., Izard, M. (ed.). Dizionario di antropologia e etnologia. Turín: Einaudi, 626-627..

Montani, R. (2021). La gente del bosque en la era de la máquina: lo residual de una misión. En Richard, N., Franceschi, Z. A., Córdoba, L., (Eds.). La misión de la máquina. Técnica, Extractivismo y Conversión en las Tierras Bajas Sudamericanas. Bologna: BUP.

Montani, R. (2017a). El mundo de las cosas entre los wichís del Gran Chaco. Un estudio etnolingüístico. Cochabamba: Itinerarios.

Montani, R. (2017b). Las verdaderas palabras de Dios en wichí. Sobre la terminología cristiana en las traducciones de los anglicanos. En Ceriani Cernadas C. (Ed.). Los evangelios chaqueños. Misiones y estrategía indígenas en el siglo XX. Buenos Aires: Rumbo Sur, 145-173.

Montani, R. (2008). La etnicidad de las cosas entre los wichís del Gran Chaco (provincia de Salta, Argentina). Indiana, 25, 117-142.

Montani, R., Combés, I. (2018). Etnonimia wichí: Cien hipótesis para mil y un nombres. Revista Andina, 56, 227-269.

Montani, R. y Juárez, G. (2016). Los días del pasado: Historias de los wichís de Morillo, San Patricio, Los Baldes / Mahnayay ta iyejen p'ante wichi ta ihi Muliyus, San Patlisyu Ihoya Kale-hi. Córdoba: La Marmosa/CIHA/ Univerdad Nacional de Córdoba.

Oakdale, S., Course, M. (2014) (Eds.). Fluent Selves: autobiography, person and history in Lowland South America. Lincoln: University of Nebraska Press.

Palmer, J. H. (2005). La buena voluntad wichí: una espiritualidad indígena. Buenos Aires: Grupo de Trabajo Ruta 81.

Pelleschi, G. (1881). Otto mesi nel Gran Ciacco: viaggio lungo il fiume Vermiglio (río Bermejo). Florencia: Tipi dell'Arte della Stampa.

Pérez, E., Wallis C. (Eds.). (2012). Educación entre los Wichí. N'ochufwenyajay ta iyej Wichi. Salta: SMA Ediciones. 
Preci, A. (2020). Fixing the territory, a turning point: The paradoxes of the Wichí maps of the Argentine Chaco. The Canadian Geographer/Le Géographe canadien, 64 (1), 20-31.

Richard, N., Franceschi, Z. A., Córdoba, L. (2021) (Eds.). La misión de la máquina. Técnica, Extractivismo y Conversión en las Tierras Bajas Sudamericanas. Bolonia: BUP.

Rohner, R. P. (1969) (Ed.). The Ethnography of F. Boas. Chicago: University of Chicago Press.

Rosaldo, M. (1980). Knowledge and Passion. Ilongot Notion of Self and Social Life. Nueva York: Cambridge University Press.

Scardozzi, C., (2015). Spazi contesi, logiche a confronto nella regione chaqueña argentina. En Meschiari M., Montes S. (Eds.). Spaction: New paradigms in spaceaction multidisciplinary research. Roma: Aracne, 1-18.

Sanjeck, R. (Ed.). (1990). Fieldnotes. The makings of Anthropology. Ithaca \& London: Cornell University Press.

Sapir, E. (1969 [1921]). Il linguaggio. Introduzione alla linguistica. Turín: Einaudi.

Scheneider A. (1998), Discours sur I'alterité dans I'Argentine modern. Cahiers Internationaux de Sociologie, vol. CV, 341-361.

Segovia, L. (2011). Olhamel ta ohopehen wichi/Nosotros, los wichi. Salta: Crivelli.

Segovia, L. (1998). Olhamel otichunhayaj. Nuestra memoria. Buenos Aires: Eudeba.

Segovia, L. (2005). Othichunaj Ihayis tha oihi tewok. Memorias del Pilcomayo. Salta: Secretaría de la Cultura de la Provincia de Salta.

Segovia, L. (2011). Olhamel ta ohopehen wichí / Nosotros, los wichís. Salta: Gráficas Crivelli.

Stocking, G. W. Jr. (1974). A Franz Boas Reader. The Shaping of American Anthropology 1883-1911. Chicago: The University of Chicago Press.

Sturzenegger, O. (1999). Le mauvais oeil de la lune: ethnomédecine créole en Amérique du Sud. París: Karthale.

Terraza, J., Cayré Baito, L. (2014). Phonological, grammatical, and written words in Wichi. Morphology, 24, 199-221.

Whorf, B.L., (1970 [1921]). Un modello d'universo degli indiani d'America. En Linguaggio, pensiero, realtà. Torino: Boringhieri, 41-49. 